\title{
Mediastinal Chondroma
}

National Cancer Institute

\section{Source}

National Cancer Institute. Mediastinal Chondroma. NCI Thesaurus. Code C6596.

A benign neoplasm composed of hyaline cartilage arising from the mediastinum. It is

characterized by the presence of chondrocytes, a lobulated growth pattern, and calcification. 